\title{
QUANTIFICAÇÃO DO CARBONO ESTOCADO NA PARTE AÉREA E RAÍZES DE Hevea sp., AOS 12 ANOS DE IDADE, NA ZONA DA MATA MINEIRA ${ }^{1}$
}

\author{
Tarcísio José Gualberto Fernandes², Carlos Pedro Boechat Soares ${ }^{3}$, Laércio Antônio Gonçalves Jacovine ${ }^{3}$ \\ e Antônio de Pádua Alvarenga ${ }^{4}$
}

\begin{abstract}
RESUMO - Este trabalho foi desenvolvido com o objetivo de quantificar o carbono estocado nos diferentes componentes das árvores de Hevea sp., na fazenda experimental da Empresa de Pesquisa Agropecuária de Minas Gerais (EPAMIG), no Município de Oratórios, Minas Gerais, servindo como base para verificar a importância da cultura no sequiestro de carbono e, conseqüentemente, na mitigação do efeito-estufa. Após as análises, verificouse que: a) os galhos contribuíram com a maior quantidade de carbono armazenado, seguido por troncos, raízes e folhas; b) existe relação exponencial positiva entre a quantidade de carbono na árvore e nos seus componentes e o seu diâmetro medido a 1,30 m do solo (dap); c) a variável dap foi significativa, a 95\% de probabilidade em todas as equações ajustadas. No entanto, a variável altura total foi significativa apenas nas equações de tronco e galhos. Complementarmente com base nos dados das parcelas, verificou-se que ao final de 12 anos o plantio de Hevea sp. consegue seqüestrar, em média, 62,10 toneladas de carbono por hectare em sua biomassa viva, considerando um espaçamento de 7 × $3 \mathrm{~m}$, ou seja, uma densidade média de 476 árvores por hectare.
\end{abstract}

Palavras-chave: Hevea sp., seqüestro de carbono e equações.

\section{QUANTIFICATION OF CARBON STORED IN THE AERIAL PART AND ROOTS OF 12-YEAR-OLD Hevea sp., IN THE “ZONA DA MATA MINEIRA"}

\begin{abstract}
The objective of this work was to quantify carbon stored in the different parts of Hevea sp. trees, in the experimental farm of the Agricultural Research Company of Minas Gerais (EPAMIG), in the Municipality of Oratorios, Minas Gerais, in order to verify the importance of the culture for carbon sequestration, and consequently for the mitigation of the greenhouse effect. The analyses showed that: a) the branches contributed with the largest amount of stored carbon, following by the stems, roots and leaves; b) a positive exponential relationship exists among the amount of carbon in the tree and in their components and the measured diameter at $1.30 \mathrm{~m}$ breast height (dbh); c) The variable dbh was significant, at the level of $95 \%$ of probability for all of the adjusted equations. However, the variable total height was significant just in the equations for the stems and the branches. Additionally, on the basis of data from the analyzed plots, it was found that after 12 years, Hevea sp. trees manage to accumulate on average 62.11 tons of carbon per hectare in its live biomass, considering a $7 \times 3 \mathrm{~m}$ spacing.
\end{abstract}

Keywords: Hevea sp., carbon sequestration and equations.

\footnotetext{
${ }^{1}$ Recebido em 08.02.2006 e aceito para publicação em 29.03.2007

${ }^{2}$ Departamento de Ciências Agrárias da Universidade Federal do Acre (UFAC). E-mail: <tarcisio@ufac.br>.

${ }^{3}$ Departamento de Engenharia Floresta da Universidade Federal de Viçosa (UFV). E-mail: <jacovine@ ufv.br $>$.

${ }^{4}$ Pesquisador da Empresa de Pesquisa Agropecuária de Minas Gerais (EPAMIG). E-mail: <padua@ epamig.ufv.br>.
} 


\section{INTRODUÇÃO}

Existe a preocupação crescente de que em meados ou no final do século XXI as agressões do homem à natureza terão mudado as condições básicas que possibilitaram o aparecimento de vida sobre a Terra. Atividades humanas como a queima de combustíveis fósseis (petróleo, carvão mineral e gás natural) e a destruição e queima das florestas estão resultando no aumento dos Gases de Efeito Estufa (GEE) na atmosfera.

Entre os GEE, o gás carbônico $\left(\mathrm{CO}_{2}\right)$ é o principal responsável pela intensificação do efeito-estufa e, portanto, pela perturbação do balanço energético entre a terra e o espaço, resultando em mudanças climáticas, as quais têm sido verificadas. Nas últimas décadas, têm-se avolumado as evidências de que o clima da Terra está ficando não só cada vez mais quente, como cada vez mais instável. Recordes contrastantes de calor e frio, seca e inundações, entre outros fenômenos climáticos, vêm sendo verificados em regiões diversas do globo, incluindo o Brasil.

A primeira tentativa de lidar com a questão climática em nível internacional aconteceu em 1988, quando foi estabelecido o Painel Intergovernamental sobre Mudança Climática (IPCC), com o objetivo de revisar e compilar informações científicas sobre o assunto. Em 1990, o IPCC lançou o primeiro relatório de avaliação, concluindo que a mudança climática era assunto premente e pedindo a criação de uma convenção que estabelecesse a base para a cooperação internacional em questões relacionadas ao aquecimento global. Assim, iniciou-se um processo de consulta e negociações que resultou no texto da Convenção Quadro das Nações Unidas sobre Mudança Climática (UNFCCC), adotado durante a Rio-92. Desde então, a convenção foi assinada por 180 países e entrou em vigor em março de 1994. Com a vigoração da UNFCCC, representantes dos países signatários passaram a se reunir anualmente para discutir o progresso de sua implementação e dar continuidade às discussões nas chamadas Conferências das Partes (COPs) (SANTILLI et al., 2002).

Entre as conferências já realizadas, destaca-se a COP - 3, ocorrida em 1997, no Japão, na qual os governos responderam efetivamente à crescente pressão pública, elaborando o Protocolo de Quioto, que é um acordo internacional independente, mas ligado a um tratado existente. Isso significa que o protocolo sobre o clima compartilha as preocupações e princípios dispostos na convenção do clima, a partir dos quais acrescenta novos compromissos, que são mais fortes e muito mais complexos e detalhados do que os anteriores. Essa complexidade reflete os enormes desafios impostos pelo controle das emissões de GEE. Também, resulta dos distintos interesses políticos e econômicos para que se chegue a um acordo (BRASIL, 2003).

O Protocolo de Quioto estabelece "mecanismos" para obter créditos a partir da redução das emissões dos gases de efeito-estufa (GEE). A idéia é de que os países que por algum motivo não possam reduzir as emissões no próprio país possam pagar por cortes nas emissões em outros lugares, através dos Certificados de Emissões Reduzidas (CERs). Entre os mecanismos propostos, destaca-se o Mecanismo de Desenvolvimento Limpo (MDL), que concederá créditos pelo financiamento de projetos que reduzam ou evitem emissões nos países em desenvolvimento. Esse mecanismo promete ser um canal importante, através do qual os governos e corporações privadas transferirão tecnologias limpas e promoverão o desenvolvimento sustentável (CEBDS, 2002).

Dentro do contexto do MDL, tem-se levado em consideração a importância das florestas como medida compensatória de emissão de gases de efeito-estufa. É de consenso científico mundial que as florestas são importantes para o equilíbrio de carbono global, pois armazenam nas árvores e no solo mais carbono do que o que existe atualmente na atmosfera (HOUGHTON, 1994). Além disso, as florestas têm como principal vantagem o fato de poderem ser manejadas para reduzir a quantidade de $\mathrm{CO}_{2}$ atmosférico e, conseqüentemente, o aquecimento global da terra.

O seqüiestro de carbono através de atividades florestais se baseia em duas premissas. Primeira, o gás carbônico é um gás atmosférico que circula no mundo todo, e, conseqüentemente, os esforços para a remoção dos GEE pelas florestas terão efeito igual, sejam eles aplicados próximos à fonte ou do outro lado do mundo. Segunda, a vegetação verde retira o gás carbônico da atmosfera através do processo da fotossíntese, convertendo-o em compostos orgânicos utilizados no crescimento e metabolismo vegetal. Dessa forma, as plantas lenhosas armazenam carbono em madeira e outros tecidos até a morte e a decomposição, fase que o carbono na madeira poderá ser desprendido na forma de gás carbônico, monóxido de carbono, ou metano, ou poderá ficar incorporado no solo como substância orgânica (COSTA et al., 1997). 
De acordo com Lugo e Brown (1980), citados por Leles (1995), a fixação de carbono, durante cada ciclo de crescimento da plantação florestal, é representada pelo aumento em biomassa, dos produtos madeireiros e não-madeireiros, os quais têm diferentes dinâmicas de crescimento. Além do reflorestamento com culturas tradicionalmente implantadas no Brasil, como o eucalipto, outras espécies podem ser consideradas efetivos sumidouros de carbono, por exemplo a seringueira (Hevea sp.).

A seringueira possui vida útil econômica de 20 a 40 anos, sendo a extensão desse período produtivo determinada, principalmente, pela intensidade de extração de látex (GARCIA e LIMA, 2000). A seringueira, além de ser uma espécie que apresenta um ciclo de produção longo e, portanto, acumula carbono por mais tempo, produz ainda o látex, que é um composto formado por carbono em sua fórmula molecular $\left(\mathrm{C}_{5} \mathrm{H}_{8}\right)$ e muito utilizado mundialmente. Segundo Burger e Smith (1996) cerca de 80 a $85 \%$ da produção do látex é utilizada na fabricação de pneumáticos; outros 20 a $15 \%$ são de usos diversos, como sapatos, adesivos, espumas, balões, preservativos etc.

O Brasil, que já foi o grande produtor de látex no começo do século, hoje tem cerca de $1 \%$ do total mundial. De acordo com Agrianual (2003), o Brasil em 2001 produziu cerca de 80 mil toneladas de borracha seca e consumiu cerca de 207,8 mil toneladas. Burger e Smith (1996) fizeram previsão de que, em termos globais, a oferta e a demanda da borracha iriam permanecer equilibradas por alguns anos. Contudo, segundo esses autores, nos primeiros anos deste milênio a demanda seria maior do que a oferta, tornando-se crítica no ano de 2020. Assim, verifica-se que há espaço para o setor de heveicultura crescer, principalmente com essa nova oportunidade, que é a implementação de seringais para a produção de látex e seqüestro de carbono.

Diante dessa situação, torna-se necessário desenvolver ou aplicar metodologias que possibilitem estimar com precisão a quantidade de carbono total em um seringal, bem como de seus diversos componentes (tronco, galhos, folhas e raízes). Nesse sentido, este trabalho foi desenvolvido com o objetivo de ajustar equações que permitem estimar a quantidade de carbono presente nos diferentes componentes das árvores de Hevea sp., servindo como base para verificar a importância da cultura no seqüestro de carbono e, conseqëentemente, na mitigação do efeito-estufa.

\section{MATERIAL E MÉTODOS}

Este estudo foi realizado em um plantio de Hevea sp. aos 12 anos de idade, localizado na Zona da Mata mineira, na fazenda experimental da Empresa de Pesquisa Agropecuária de Minas Gerais (EPAMIG), no Vale do Piranga, no Município de Oratórios, MG. Os clones analisados foram o FX 3864, FX 2261 e IAN 873, plantados no espaçamento de 7 × 3 m (476 árvores por hectare). A área em questão, de aproximadamente 10 ha, está situada a $20^{\circ} 30^{\prime}$ de latitude $\mathrm{S}$ e $43^{\circ} 00^{\prime}$ de longitude e com altitude de $500 \mathrm{~m}$, temperatura média anual de $19,5^{\circ} \mathrm{C}$ e a precipitação média anual de $1.250 \mathrm{~mm}$. Segundo Köppen, o clima da região varia do tipo Cwa, tropical úmido, a Aw, semi-húmido de verões quentes. A vegetação natural, já retirada para o plantio do seringal, era de floresta tropical semidecidual ou ombrófila mista.

De acordo com Cunha et al. (2000), a caracterização estrutural e analítica dos solos investigados, na mesma área de estudo, permite distinguir três domínios pedogenéticos: a) um domínio latossólico fortemente intemperizado e rico em caulinita; b) um domínio intermediário latossólico-podzolizado relativamente mais fracamente intemperizado e relativamente mais rico em minerais primários; c) um domínio de acumulação, podzólico. O domínio latossólico ocupa a maior parte das encostas e os topos das colinas. O domínio intermediário latossólico-podzolizado situa-se à meia vertente, e o domínio podzólico ocupa o resto do modelado, ou seja, o terço inferior das encostas e o sopé destas até os eixos de drenagem.

Foram locadas aleatoriamente 27 parcelas de 252 $\mathrm{m}^{2}$ cada, com o objetivo de caracterizar as distribuições diamétricas das árvores, para selecionar as árvoresamostra. Para uma melhor representatividade da condição real do seringal, foram selecionadas seis árvores-amostra, representando as classes diamétricas em cada um dos três domínios pedogenéticos da área, num total de 18 árvores-amostra representativas da população.

Para determinação da biomassa e do conseqüente acúmulo de carbono, utilizou-se o método direto, o qual consiste na derrubada e pesagem de todos os componentes de uma árvore-amostra. Cada árvore foi abatida rente ao solo, e forampesados os vários componentes: tronco, galho grosso (diâmetro maior que $3 \mathrm{~cm}$ ), galho fino (diâmetro menor que $3 \mathrm{~cm}$ ), folhas e raízes. Subseqüentemente, foram selecionadas e coletadas amostras de todos os componentes para determinação do peso de matéria seca. As amostras

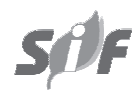

R. Árvore, Viçosa-MG, v.31, n.4, p.657-665, 2007 
de tronco foram coletadas na forma de discos de madeira da base, meio e topo.

A partir dos dados de biomassa de cada parte amostrada da árvore, obtidos pelo método direto, pôde-se estimar as respectivas quantidades de carbono, multiplicando as estimativas de biomassa por um fator 0,50 (LELES et al., 1994; REIS et al., 1994 e HUSCH, 2001).

De posse das estimativas da quantidade de carbono presente no tronco, nos galhos, nas folhas, nas raízes e no total de cada árvore-amostra de Hevea sp foram elaborados gráficos relacionando às quantidades de carbono com a altura total $(\mathrm{Ht})$ e também com o diâmetro com casca das árvores a 1,3 m do solo (dap), objetivando a determinação das relações funcionais que possibilitem a estimação da quantidade de carbono presente nas diversas partes.

As relações funcionais foram ajustadas e avaliadas através do coeficiente de variação (CV\%), do coeficiente de determinação $\left(R^{2}\right)$ edaanálise gráfica de resíduos porcentuais.

Após ajustadas as equações para o tronco, os galhos, as folhas, as raízes e o carbono total, estas foram aplicadas nas parcelas com vista a obter uma estimativa média por parcela, bem como por hectare da quantidade de carbono armazenadoe, ainda, fornecer uma estimativa da variabilidade dos dados em torno da média.

\section{RESULTADOS E DISCUSSÃO}

Analisando as estimativas das quantidades médias gerais de carbono presentes no tronco, nos galhos, nas folhas e nas raízes das árvores-amostra de Hevea sp. apresentadas no Quadro 1, verificou-se que os galhos contribuíram com maior percentual de carbono na árvore $(35,9 \%)$, seguidos por tronco $(30,1 \%)$, raízes $(29,9 \%)$ e folhas $(4,1 \%)$.

Quadro 1 - Estimativas da quantidade de carbono no tronco, nos galhos, nas folhas e nas raízes e do carbono total das árvores-amostra de Hevea sp.

Table 1 - Estimates of the amount of carbon in the stem, branches, leaves, roots and total carbon of the Hevea sp. treesamples

\begin{tabular}{|c|c|c|c|c|c|c|c|c|}
\hline \multirow[b]{2}{*}{ Árvore } & \multirow[b]{2}{*}{ Classe dap } & \multirow[b]{2}{*}{ dap } & \multirow[b]{2}{*}{$H t$} & \multicolumn{5}{|c|}{ Carbono $(\mathrm{Kg})$} \\
\hline & & & & Tronco & Galhos & Folhas & Raízes & Total \\
\hline 1 & \multirow{4}{*}{12,5} & 13,8 & 15,3 & 32,3 & 10,6 & 2,2 & 25,9 & 70,9 \\
\hline 2 & & 14,0 & 12,0 & 23,7 & 14,1 & 2,5 & 47,2 & 87,4 \\
\hline 3 & & 14,3 & 8,4 & 19,1 & 24,7 & 3,6 & 26,9 & 74,3 \\
\hline \multirow[t]{3}{*}{4} & & 14,5 & 12,3 & 31,4 & 20,4 & 2,8 & 18,6 & 73,1 \\
\hline & \multirow{2}{*}{$\begin{array}{c}\text { Média } \\
\% \text { Carbono }\end{array}$} & 14,2 & 12,0 & 26,6 & 17,4 & 2,8 & 29,6 & 76,4 \\
\hline & & & & 34,8 & 22,8 & 3,6 & 38,8 & 100 \\
\hline 5 & \multirow{11}{*}{17,5} & 15,6 & 12,7 & 32,5 & 18,0 & 3,3 & 42,4 & 96,2 \\
\hline 6 & & 15,6 & 12,9 & 43,5 & 46,5 & 3,9 & 36,8 & 130,8 \\
\hline 7 & & 15,9 & 11,9 & 29,1 & 44,8 & 4,3 & 34,4 & 112,6 \\
\hline 8 & & 15,9 & 11,4 & 34,2 & 62,3 & 5,1 & 27,4 & 129,0 \\
\hline 9 & & 16,2 & 13,9 & 44,1 & 40,0 & 8,6 & 31,9 & 124,5 \\
\hline 10 & & 16,6 & 10,4 & 27,4 & 34,6 & 10,0 & 31,1 & 103,0 \\
\hline 11 & & 16,6 & 11,7 & 29,1 & 54,5 & 5,5 & 28,9 & 117,9 \\
\hline 12 & & 16,9 & 12,4 & 38,4 & 27,0 & 2,2 & 44,5 & 112,1 \\
\hline 13 & & 19,4 & 9,5 & 31,4 & 78,7 & 11,2 & 44,0 & 165,3 \\
\hline 14 & & 19,4 & 11,1 & 36,3 & 78,4 & 7,5 & 60,6 & 182,8 \\
\hline \multirow[t]{3}{*}{15} & & 19,7 & 17,2 & 60,1 & 44,6 & 6,7 & 71,1 & 182,6 \\
\hline & \multirow{2}{*}{$\begin{array}{c}\text { Média } \\
\% \text { Carbono }\end{array}$} & 17,1 & 12,3 & 36,9 & 48,1 & 6,2 & 41,2 & 132,4 \\
\hline & & & & 27,9 & 36,3 & 4,7 & 31,1 & 100 \\
\hline 16 & \multirow{3}{*}{22,5} & 20,1 & 15,5 & 68,4 & 56,9 & 5,5 & 59,7 & 190,5 \\
\hline 17 & & 20,7 & 12,7 & 59,2 & 117,1 & 8,8 & 33,4 & 218,4 \\
\hline \multirow[t]{5}{*}{18} & & 21,7 & 14,5 & 77,6 & 85,9 & 6,0 & 50,6 & 220,0 \\
\hline & Média & 20,8 & 14,2 & 68,4 & 86,6 & 6,8 & 47,9 & 209,6 \\
\hline & $\%$ Carbono & & & 32,6 & 41,3 & 3,2 & 22,9 & 100 \\
\hline & $\begin{array}{l}\text { Média Geral } \\
\text { Ponderada }\end{array}$ & 17,1 & 12,6 & 39,9 & 47,7 & 5,5 & 39,7 & 132,8 \\
\hline & $\%$ Carbono & & & 30,1 & 35,9 & 4,1 & 29,9 & 100 \\
\hline
\end{tabular}

R. Árvore, Viçosa-MG, v.31, n.4, p.657-665, 2007 
Quando se analisa em função da classe diamétrica, verificou-se que os porcentuais médios de contribuição se alteram (Quadro 1 e Figura 1). Na classe de 12,5 $\mathrm{cm}$ de dap, a raiz representa o maior porcentual $(38,8 \%)$, seguido por tronco $(34,8 \%)$, galhos $(22,8 \%)$ e folhas $(3,6 \%)$. Na classe de $17,5 \mathrm{~cm}$ de dap, os galhos contribuíram mais $(36,3 \%)$, seguidos pelas raízes $(31,1 \%)$, pelo tronco $(27,9 \%)$ e folhas $(4,7 \%)$. Na classe de 22,5 , os galhos continuam sendo o componente que mais contribui para o carbono total armazenado $(41,3 \%)$, no entanto, diferentemente da classe de 17,5, é seguido pelo tronco $(32,6 \%)$, pelas raízes $(22,9 \%)$ e pelas folhas $(3,2 \%)$. Essa variação se deve à posição das árvores dentro dos plantios. Árvores menores normalmente têm um porcentual de biomassa alocado para o sistema radicular em detrimento da parte aérea.

Soares e Oliveira (2002) encontraram, em plantios com o gênero Eucalyptus, que o tronco foi o componente que contribuiu com o maior porcentual de carbono armazenado. No entanto, para a seringueira, cujas práticas silviculturais são aplicadas buscando maior produção de galhos e folhas, ou seja, maior produção de copa para maior área fotossintética e maior produção de látex, os galhos possuem contribuição diferenciada no armazenamento de biomassa e, conseqüentemente, no carbono total.

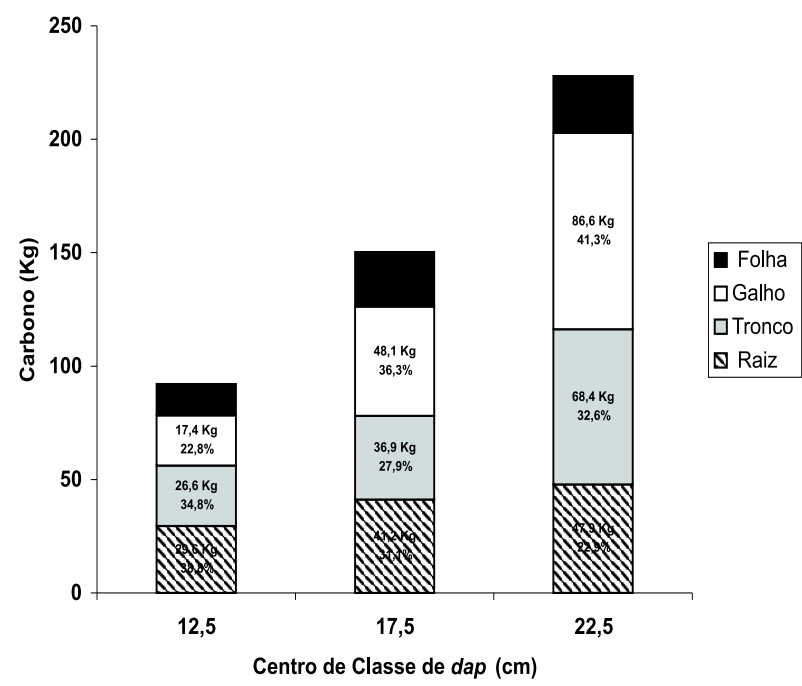

Figura 1 - Distribuição do carbono armazenado em quilograma e porcentagem, para cada componente, por classe de dap.

Figure 1 -Distribution of the carbon stored in kilogram and percentage, for each component, per class of $d b h$.
De acordo com os resultados obtidos no Quadro 1 , verificou-se que, em média, nessas condições um seringal armazena $132,8 \mathrm{~kg}$ de carbono por árvore aos 12 anos. Ao aplicar a equação para o carbono total nas 27 parcelas alocadas (Quadro 2), verificouse que aos 12 anos de idade um seringal armazena em média 62,10 toneladas de Carbono por hectare (tC/ha). Rahaman e Sivakumaran (1998), em seu estudo realizado em Bali, Indonésia, encontraram 92,8 tC/ ha, ao final de 30 anos.

Reis et al. (1994) citaram que a cultura do eucalipto, espécie mais plantada no Brasil e no mundo e forte candidata ao mercado de créditos de carbono, acumula aproximadamente 31,4 tC/ha na região do Cerrado do Estado de Minas Gerais, considerando uma rotação de sete anos. Ladeira et al. (2001), para o mesmo gênero, idade e região, encontrou valores entre 24,7 e 49,1 tC/ha, para plantios com área por planta variando de $4,5 \mathrm{~m}^{2} \mathrm{a} 12 \mathrm{~m}^{2}$.

Com os dados do Quadro 1, elaboraram-se gráficos de dispersões (Figuras 2 e 3), os quais indicam uma relação exponencial positiva entre a quantidade de carbono presente nas diferentes partes da árvore (Y) e o seus daps (Figura 2), o que pode ser representada pela seguinte relação alométrica, de acordo com Vann et al. (1993).

$$
\mathrm{Y}=\beta o \cdot \operatorname{dap}^{\beta 1} . \varepsilon
$$

Já a variável altura total $H t$ (Figura 3 ) mostrouse não ser uma variável adequada para o ajuste, tendo em vista a grande dispersão observada. No entanto, como árvores de mesmo diâmetro (dap) podem apresentar diferentes quantidades de carbono, haja vista os resultados do Quadro 1, pode-se adicionar à expressão (1) a variável altura total $(H t)$, ficando, assim, redefinida:

$$
\mathrm{Y}=\beta o \cdot \operatorname{dap}^{\beta 1} \cdot H t^{\beta 1} \cdot \varepsilon
$$

em que:

$\mathrm{Y}=$ carbono, em kg;

$\beta o, \beta 1$ e $\beta 2$ = parâmetros do modelo;

$d a p=$ diâmetro a 1,3 $\mathrm{m}$ do solo, em cm;

$H t=$ altura total, em m; e

$\varepsilon=$ erro aleatório.

A expressão 2 pode ser caracterizada como uma variação do modelo volumétrico de Shumacher e Hall (1933), no qual, em vez de estimar o volume das árvores, estima-se a quantidade de carbono presente em diferentes partes da planta.

R. Árvore, Viçosa-MG, v.31, n.4, p.657-665, 2007 
Quadro 2 - Estimativas da quantidade de carbono em kg por hectare no tronco, nos galhos, nas folhas e nas raízes e do carbono total das parcelas amostradas de Hevea sp.

Table 2 - Estimates of the amount of carbon in kilogram per hectare in the stem, branches, leaves, roots and total carbon of sampled Hevea sp. plots

\begin{tabular}{|c|c|c|c|c|c|}
\hline \multirow[t]{2}{*}{ Parcela } & \multicolumn{5}{|c|}{ Carbono em Kg } \\
\hline & Tronco & Galhos & Folhas & Raízes & Total \\
\hline 1 & $28.579,21$ & $34.607,02$ & $3.074,44$ & $22.616,99$ & $90.620,66$ \\
\hline 2 & $29.542,56$ & $33.791,79$ & $2.974,07$ & $23.288,75$ & $91.140,36$ \\
\hline 3 & $25.064,16$ & $26.499,06$ & $2.434,88$ & $20.041,46$ & $74.564,58$ \\
\hline 4 & $14.019,57$ & $11.435,46$ & $1.578,87$ & $14.241,62$ & $41.780,71$ \\
\hline 5 & $11.813,24$ & $6.560,04$ & $1.044,58$ & $11.709,02$ & $29.821,66$ \\
\hline 6 & $12.055,37$ & $6.668,14$ & $1.077,97$ & $12.031,80$ & $30.829,31$ \\
\hline 7 & $24.983,67$ & $32.452,63$ & $3.113,82$ & $21.944,40$ & $84.651,87$ \\
\hline 8 & $26.854,19$ & $31.370,59$ & $2.910,38$ & $22.389,85$ & $84.473,38$ \\
\hline 9 & $26.754,39$ & $33.569,85$ & $3.079,17$ & $22.447,93$ & $87.384,10$ \\
\hline 10 & $19.105,56$ & $22.349,00$ & $2.382,96$ & $17.936,33$ & $63.445,84$ \\
\hline 11 & $17.380,53$ & $20.213,91$ & $2.127,62$ & $16.157,88$ & $57.050,20$ \\
\hline 12 & $22.985,43$ & $27.684,21$ & $2.675,60$ & $20.064,55$ & $74.770,44$ \\
\hline 13 & $9.061,06$ & $5.079,49$ & 777,85 & $8.867,01$ & $22.436,93$ \\
\hline 14 & $15.538,66$ & $15.731,40$ & $1.868,89$ & $15.230,64$ & $49.349,74$ \\
\hline 15 & $15.166,68$ & $14.864,76$ & $1.686,01$ & $14.301,83$ & $45.754,78$ \\
\hline 16 & $20.782,24$ & $20.179,08$ & $2.103,16$ & $18.108,69$ & $61.594,84$ \\
\hline 17 & $12.710,21$ & $12.147,89$ & $1.364,10$ & $11.766,53$ & $37.788,90$ \\
\hline 18 & $16.934,48$ & $18.886,18$ & $1.967,73$ & $15.368,72$ & $53.608,95$ \\
\hline 19 & $25.218,51$ & $28.537,44$ & $2.745,17$ & $20.966,83$ & $79.147,45$ \\
\hline 20 & $28.219,16$ & $32.881,62$ & $3.038,59$ & $23.187,01$ & $88.473,95$ \\
\hline 21 & $26.426,33$ & $32.048,28$ & $3.090,37$ & $22.851,38$ & $86.414,13$ \\
\hline 22 & $14.559,33$ & $14.236,55$ & $1.676,49$ & $14.065,77$ & $44.458,96$ \\
\hline 23 & $16.512,18$ & $14.639,05$ & $1.720,38$ & $15.443,16$ & $48.192,34$ \\
\hline 24 & $20.130,43$ & $22.962,13$ & $2.410,13$ & $18.601,87$ & $64.831,33$ \\
\hline 25 & $22.844,43$ & $24.057,97$ & $2.316,62$ & $19.145,24$ & $68.385,77$ \\
\hline 26 & $18.003,59$ & $18.923,53$ & $2.203,87$ & $17.407,77$ & $58.039,20$ \\
\hline 27 & $18.448,55$ & $19.548,63$ & $2.143,11$ & $17.251,13$ & $57.884,06$ \\
\hline Media & $19.988,66$ & $21.552,80$ & $2.206,92$ & $17.682,75$ & $62.107,20$ \\
\hline Variância & $34.948 .108,38$ & $82.624 .382,20$ & $472.758,11$ & $16.797 .103,68$ & $419.637 .255,65$ \\
\hline Desvio & $5.911,69$ & $9.089,80$ & 687,57 & $4.098,43$ & $20.485,05$ \\
\hline $\mathrm{CV}$ & 29,58 & 42,17 & 31,16 & 23,18 & 32,98 \\
\hline
\end{tabular}

Por facilidade de ajuste, o modelo 2 foi ajustado em sua forma linear, obtendo-se as seguintes estimativas dos parâmetros e respectivas medidas de precisão:

Tronco:

LnC Tronco $=-4,07305+1,63781 . \operatorname{Ln}(\text { dap })^{*}+1,21724 \cdot \operatorname{Ln}(H t)^{*}$ $\mathrm{R}^{2}=89,19 \% \quad \mathrm{CV}=12,65 \%$

Galhos:

LnC Galhos $=-5,50875+4,23631 . \operatorname{Ln}(\text { dap })^{*}-1,10913 . \operatorname{Ln}(H t)^{*}$ $\mathrm{R}^{2}=74,13 \% \quad \mathrm{CV}=29,43 \%$

Folhas:

LnCFolhas $=-3,77312+2,80234 \cdot \operatorname{Ln}(\text { dap })^{*}-1,01728 \cdot \operatorname{Ln}(H t)^{\text {n.s }}$ $\mathrm{R}^{2}=51,32 \% \quad \mathrm{CV}=38,87 \%$

Raízes:

Ln C raízes $=-1,47682+1,44837 . \operatorname{Ln}(\text { dap })^{*}+0,40104 \cdot \operatorname{Ln}(H t)^{\text {n.s }}$ $\mathrm{R}^{2}=38,31 \% \quad \mathrm{CV}=27,33 \%$
Total:

Ln C Total $=-2,35205+2,43795 \cdot \operatorname{Ln}(\text { dap })^{*}+0,11394 \cdot \operatorname{Ln}(H t)^{\mathrm{n} . \mathrm{s}}$ $\mathrm{R}^{2}=90,37 \% \quad \mathrm{CV}=9,53 \%$

Pode-se verificar que o modelo proposto para estimar a quantidade de carbono expressou alto grau de ajuste, para carbono total e para tronco das árvores (maior $\mathrm{R}^{2}$ ), com menor poder de explicação para galhos, seguido pelas folhas e raízes.

A variável dap foi significativa a $95 \%$ de probabilidade em todas as equações ajustadas $(\text { dap })^{*}$, confirmando-se como variável importante nos modelos para estimar a quantidade de carbono das diversas partes da espécie Hevea sp. A variável altura total $(H t)$, por sua vez, foi significativa apenas nas equações que estimam a quantidade de carbono no tronco e nos galhos. 

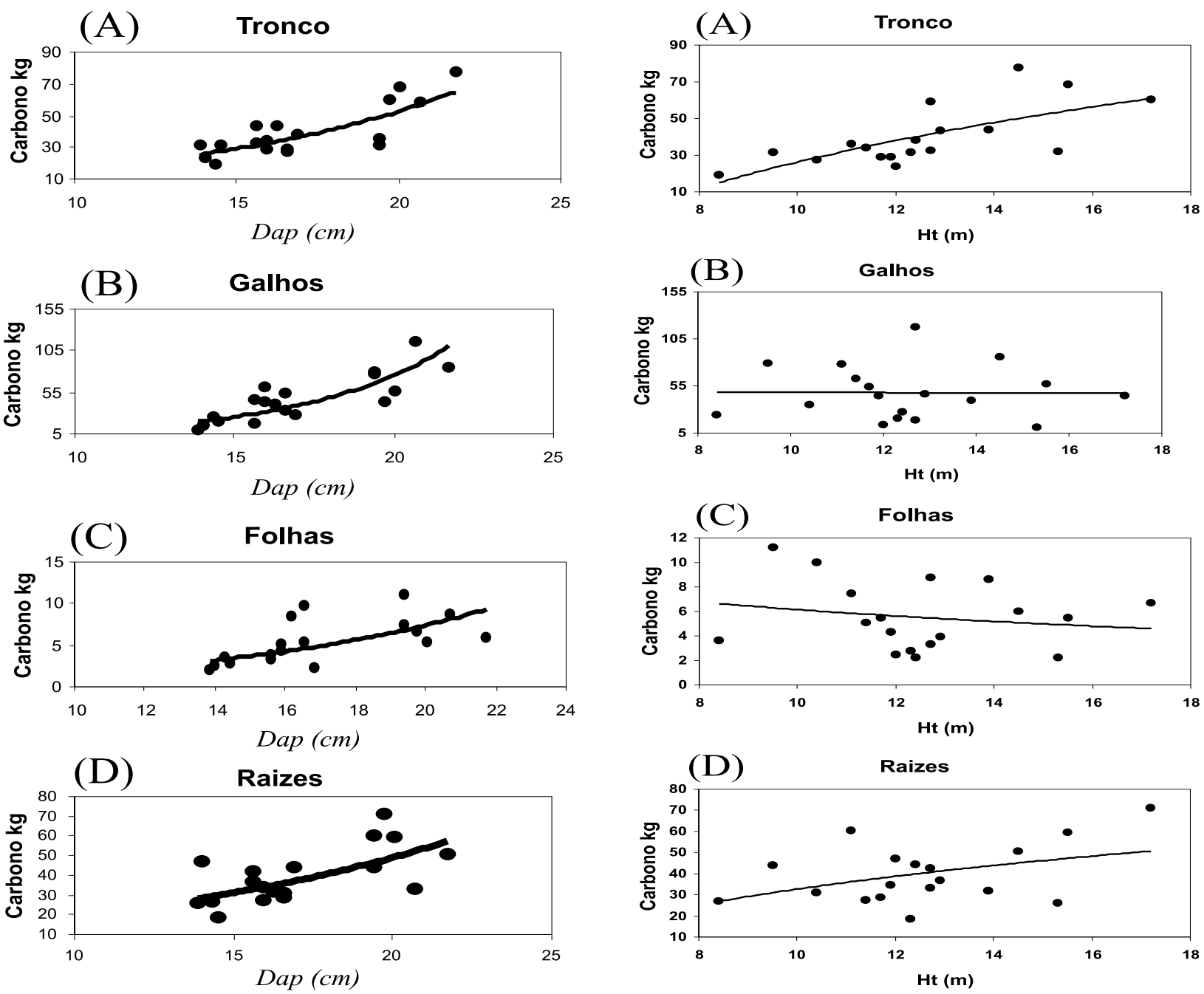

(E) Carbono Total

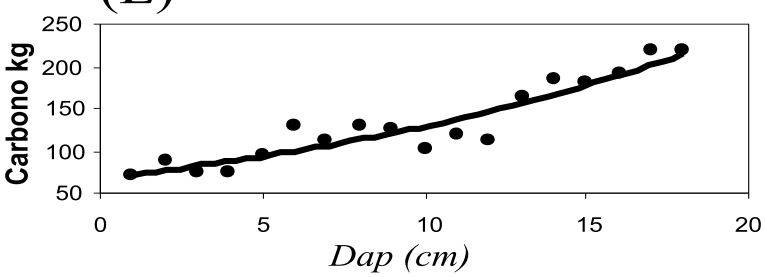

Figura 2 - Gráficos de dispersão das quantidades de carbono presentes no tronco (A), nos galhos (B), nas folhas (C), raízes (D) e de carbono total (E), em função dos diâmetros (dap) das árvores-amostra de Hevea sp., aos 12 anos de idade.

Figure 2-Dispersion graphs for the amounts of carbon present in the stems $(A)$, branches $(B)$, leaves $(C)$, roots $(D)$ and total carbon $(E)$, as a function of the diameters (dbh) of Hevea sp. tree-samples, at 12 years of age.

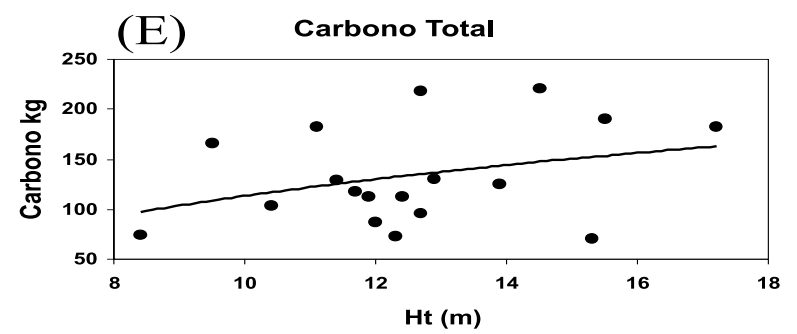

Figura 3 - Gráficos de dispersão das quantidades de carbono presentes no tronco (A), nos galhos (B), nas folhas (C), nas raízes (D) e de carbono total (E), em função da altura total $(\mathrm{Ht})$ das árvores-amostra de Hevea sp., aos 12 anos de idade.

Figure 3 -Dispersion graphs for the amounts of carbon present in the stems $(A)$, branches $(B)$, leaves $(C)$, roots $(D)$ and total carbon (E), as a function of the total height (Ht) of Hevea sp. tree-samples, at 12 years of age.

R. Árvore, Viçosa-MG, v.31, n.4, p.657-665, 2007 
A não-significância ( $)^{\text {ns }}$ dessa variável na equação das folhas, de acordo com Soares e Oliveira (2002), pode estar relacionada a outros aspectos, a exemplo da estação do ano em que foram coletados os dados (caducifolismo). Além disso, esse resultado indica a necessidade de inclusão e teste de outras variáveis nos modelos ajustados para Hevea sp., por exemplo o diâmetro de copa e a altura da copa.
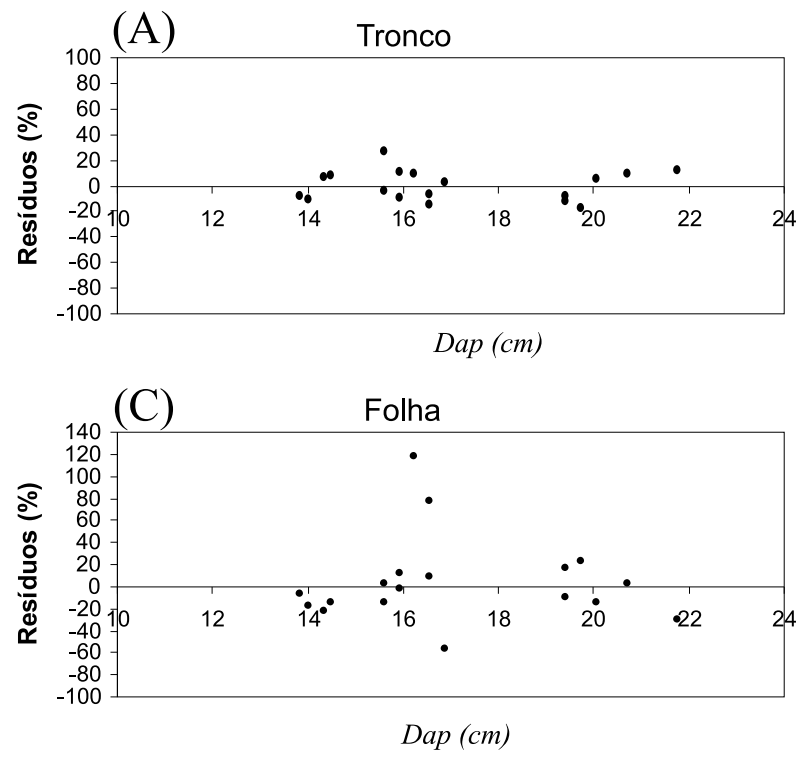

Analisando os gráficos de resíduos apresentados na Figura 4, observa-se que ocorre distribuição homogênea dos resíduos e próximos de zero para tronco e carbono total (Figura 4A-E). Para galhos e folhas (Figura 4B-C), além da maior amplitude dos resíduos, há a tendência de subestimação das quantidades de carbono para as menores árvores. Nas raízes (Figura 4D), embora os resíduos estejam distribuídos sem tendências, há grande amplitude de distribuição.
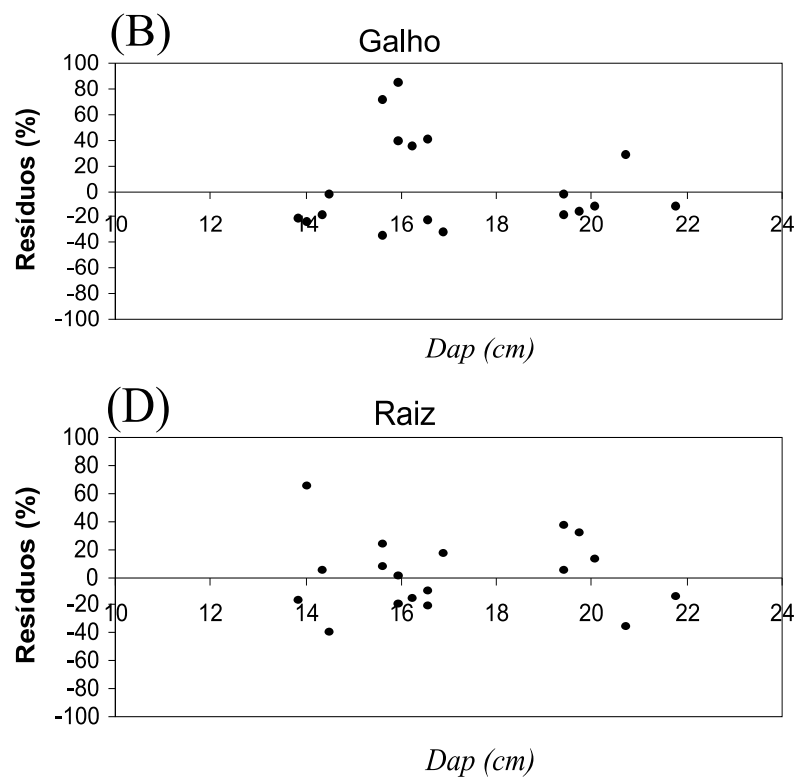

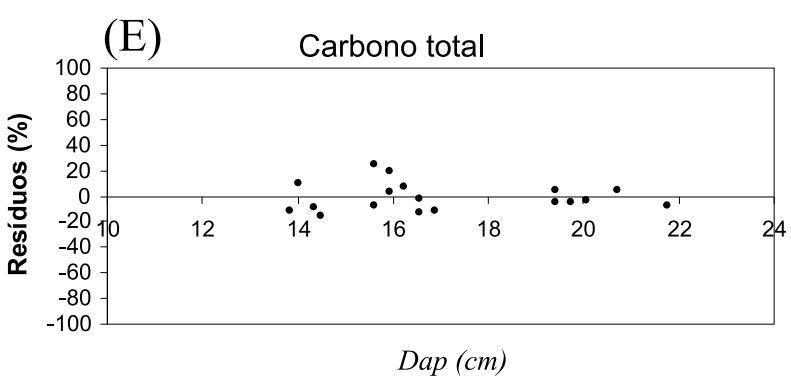

Figura 4 - Distribuição dos resíduos porcentuais das equações ajustadas do tronco (A), dos galhos (B), das folhas (C), das raízes (D) e de carbono total (E), em função dos diâmetros (dap) das árvores-amostra de Hevea sp, aos 12 anos de idade.

Figure 4 - Distribution of percentual residues of the adjusted equations for stems $(A)$, branches (B), leaves $(C)$, roots $(D)$ and total carbon (E), as a function of the diameters (dbh) of Hevea $\mathrm{sp}$ tree-samples, at 12 years of age.

\section{CONCLUSÕES}

Após as análises, verificou-se que: a) os galhos contribuíram com a maior quantidade de carbono armazenado, seguido por troncos, raízes e folhas; b) existe uma relação exponencial positiva entre a quantidade de carbono na árvore e nos seus componentes e o seu dap; c) a variável dap foi significativa, no nível de 95\% de probabilidade, para todas as equações ajustadas. No entanto, a variável altura total foi significativa apenas nas equações do tronco e dos galhos; d) ao final de 12 anos, o plantio de Hevea sp. seqüestrou, em média, 62,10 toneladas de carbono por hectare em sua biomassa viva. 


\section{REFERÊNCIAS}

\section{ANUÁRIO DA AGRICULTURA \\ BRASILEIRA - AGRIANUAL 2003. São Paulo: \\ FNP consultoria \& Comercio, 2003. p.453-462.}

BRASIL. Ministério da Ciência e Tecnologia. O

Protocolo de Quioto. Disponível em:< http:/ /www.mct.gov.br/clima/quioto/protocol.htm>, acessado em 05 de fevereiro de 2003.

BURGER, K.; SMITH, H. P. The natural rubber market review, analysis, polices and outlook. Cambridge: Woodhead Publishing, 1996. 137p.

CONSELHO EMPRESARIAL BRASILEIRO PARA ODESENVOLVIMENTO SUSTENTÁVEL-CEBDS.

Mecanismo de Desenvolvimento

Limpo. Rio de Janeiro: 2002. 35p.

CUNHA, T. J. F. et al. Influência da diferenciação pedológica no desenvolvimento da seringueira no município de Oratórios, MG. Pesquisa Agropecuária Brasileira, v.35, n.1, p.145-155, 2000.

GARCIA, N. C. P.; LIMA, P. C. Cultura da seringueira. Viçosa, MG: EPAMIG/CTZM, 2000. 13p. (Apostila da $71^{a}$. Semana do Fazendeiro).

HOUGHTON, R. A. As florestas e o ciclo de carbono global: Armazenamento e emissões atuais. In: SEMINÁRIO EMISSÃO X SEQÜESTRO $\mathrm{DE} \mathrm{CO}_{2}$ : uma oportunidade de negócios para o Brasil, 1994, Rio de Janeiro. Anais... Rio de Janeiro: CVRD, 1994. p.40-75.

HUSCH, B. Estimacion del contenido de carbono de los bosques. In: SIMPOSIO INTERNACIONAL MEDICIÓN Y MONITOREO DE LA CAPTURA DE CARBONO EN ECOSISTEMAS FORESTALES, 2001. Anais... Valdivia: 2001. p.87-91.

LADEIRA, B. C. et al. Produção de biomassa de eucalipto sob três espaçamentos, em uma seqüência de idade. Revista Árvore, v.25, n.1, p.69-78, 2001.
LELES, P. S. S.; OLIVEIRA NETO, S. N.; SILVA, E. Captura e fluxo de $\mathrm{CO}_{2}$ atmosférico pelas florestas plantadas e manejadas. Viçosa, MG: SIF, 1994. 13p. (Boletim técnico, 7).

LELES, P. S. S. Crescimento, Alocação de biomassa e distribuição de nutrientes e uso da água em E. camaldulensis $e$ E. pellita sob diferentes espaçamentos. 1995. 133f. Dissertação (Mestrado em Ciência Florestal) - Universidade Federal de Viçosa, Viçosa, MG, 1995.

RAHAMAN, W. A.; SIVAKUMARAN, S. Studies of carbon sequestration in rubber. UNCTAD/ IRSG RUBBER FORUM, 1998, Bali. Paper...Bali, Indonesia.,1998.

REIS, M. G. F. et al. Seqüestro e armazenamento de carbono em florestas nativas e plantadas nos estados de Minas Gerais e Espirito Santo. In: SEMINÁRIO EMISSÃO X SEQÜESTRO DE CO $\mathrm{CO}_{2}$ : uma oportunidade de negócios para o Brasil. 1994, Rio de Janeiro. Anais... Rio de Janeiro: CVRD, 1994. p.155-195.

SANTILLI, M.; CARVALHO, G.; NEPSTAD, D. O Brasil e as mudanças climáticas globais. In: CAMARGO, A.; CAPOBIANCO, J. P. R.; OLIVEIRA, J. A. P. (Orgs). Meio ambiente Brasil - avanços e obstáculos pós-Rio92. São Paulo: Estação Liberdade, Instituto Socioambiental. Rio de Janeiro: Fundação Getúlio Vargas, 2002. p.57-68.

SCHUMACHER, F. X.; HALL, F. S.

Logarithmic expression of timber-tree volume. Journal of Agricultural Research, v.47, n.9, p.719-734, 1933.

SOARES C. P. B.; OLIVEIRA, M. L. R. Equações para estimar a quantidade de carbono na parte aérea de árvores de eucalipto em Viçosa, Minas Gerais Revista Árvore, v.26, n.5, p.533-539, 2002.

VANN, D. R.; PÁLMIOTTO, P. A.; STRIMBECK, G. R. Allometric equations for two South American conifers: Test of a non-destructive methods. Forest Ecology and Management, v.106, p.55-71, 1998.

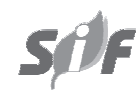

R. Árvore, Viçosa-MG, v.31, n.4, p.657-665, 2007 
